Case Report

\title{
Improvement facial aesthetics with immediate denture treatment
}

\author{
I Ketut Budi Santosa, Rostiny, Eha Djulaeha \\ Department of Prosthodontics, Faculty of Dental Medicine \\ Universitas Airlangga \\ Surabaya - Indonesia
}

\begin{abstract}
Background: immediate dentures are one of denture treatment that provides a rapid treatment stage to improve aesthetics without patients experiencing toothless phase due the tooth is extraction or decaputated. Purpose: To reported maxillary immediate partial denture and mandibulary immediate complete overdenture with magnetic retention to improve facial aesthetics. Case: A-56 years old woman with twelve tooth loss $(17,16,15,26,34,35,36,37,44,45,46,47)$ and have fillings teeth on 21,11 and 12 patched in dental artisans less more than 1 year and now its felt swollen with mobility $3^{0}$ in the last few weeks and teeth 31,41,42,43 experienced mobilitys $2^{0}$ due to calculus and teeth 32,33 were deep caries with mobility $3^{0}$. Case Management: in phanoramic photo teeth 11,21 and 22 saw a large periapical lesion $\emptyset 10 \mathrm{~mm}$ and its advised to extract. In 32 and 33, non-immediate extraction was performed because periapical lesions and deep caries are large enough with the presence of periapical abscesses, while teeth 31, 41, 42 and 43 are scaling and rootplaning then endodontic treatment is performed to obtain a harmonious relationship between the upper anterior teeth and below the teeth 31,41.42.43 is immediately decaputated and restored with GI cement on the surface of the teeth and magnet keeper coping was done for 43. Discussion: The main objective of the immediate denture treatment is to avoid psychological, social and discomfort from look toothless Conclusion: Immediate denture is the choice of treatment to improve the retention and facial aesthetic..
\end{abstract}

Keywords: esthetics, extraction, immediate, overdenture,

Correspondence: Rostiny, Department of Prosthodontics, Faculty of Dental Medicine, Universitas Airlangga, Jl. Prof. Dr. Moestopo No. 47 Surabaya 60132 - Indonesia, Phone: +62315030255 Email: rostiny@ fkg.unair.ac.id

\section{INTRODUCTION}

Prosthodontic treatment is a dental and oral rehabilitation treatment that aims to restore the function of teeth and surrounding tissues such as the function of chewing, talking and aesthetics by replacing part or all of the teeth and soft tissues with artificial gums. ${ }^{1}$ One of the treatments in the field of prostodontia is immediate extraction and immediate overdenture, which is the making of dentures immediately after the teeth cannot be maintained or the teeth projected as supporting tissues have been extracted or cut (decaputation). ${ }^{1,2,3}$ Immediate denture is a denture made first and immediately inserted into the mouth of the patient immediately after extraction or decaputation of the tooth.,4

Meanwhile, immediate overdenture (decaputation) treatment using a bare root overdenture design that is the remaining dental tissue treated with root canal in a spat using Glass Ionomer Cement which is placed just close the orifice immediately after the crown cutting is done for time efficiency and visits from sufferers. Overdenture can increase support and stability of the prosthesis, prolong the life of the support teeth and inhibit residual ridge resorption ${ }^{4}$

This paper aims to provide information about management of an immediate partial denture treatment in the maxilla and an immediate complete overdenture with magnetic retention in the mandible to improve facial aesthetics.

\section{CASE}

A 56-year-old woman came to Airlangga University Dental Hospital Surabaya clinic to make dentures to chew well and improve appearance, complaining the upper and lower front teeth mobility and want to be extracted but she dont want look toothless because the patient is actively socializing and have limited visiting hours. She want a short treatment but still give a satisfactory result.. She have missing teeth on $17,16,15,26,34,35,36,37,44$, 


\section{Indonesian Journal of Dental Medicine}

Volume 1 Issue 1 2018; 49-53

45,46,47 and fillings on teeth 21,11 and 12 patched in dental artisans approximately 1 year ago. The last few weeks felt swollen with unsteadiness $3^{0}$ and teeth $31,41,42,43$ experienced unsteadiness due to calculus and teeth 32,33 there were profuse caries accompanied by tooth mobility $3^{0}$.

Patient profile from front view (Figure 1a) and side view (Figure 1b) and the initial condition of the patient's teeth was show in figure $1 \mathrm{c}-\mathrm{d}$. Also we can see the occlusal view from upper jaw (Figure 2a) and lower (Figure $2 \mathrm{~b})$ and the panoramic photos of patient in Figure 2c. In panoramic photo it was looks a periapical lesions that are quite large $\varnothing 10 \mathrm{~mm}$ in the apical of 11.21 and 22.

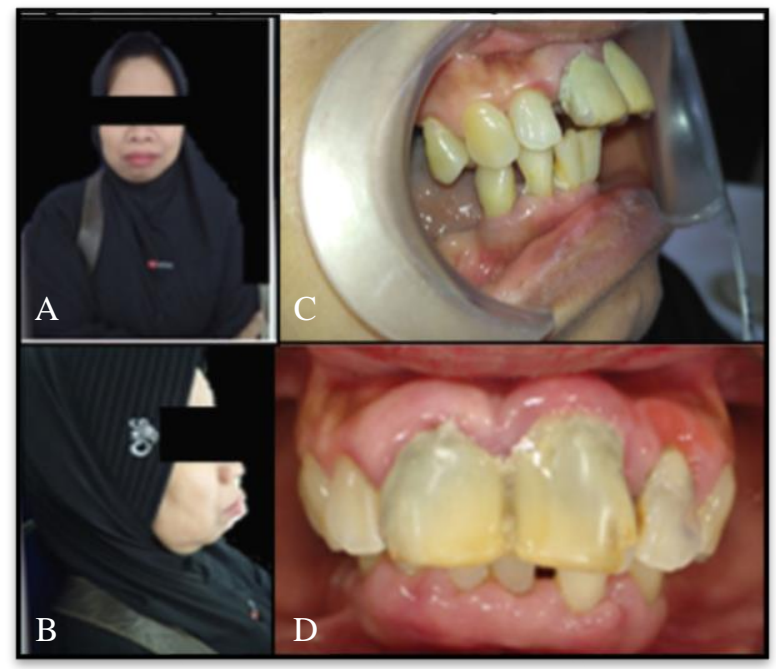

Figure 1. Patient profile: (A) front view and (B) side view; initial condition of the patient's teeth: (C) Side view (D) front view

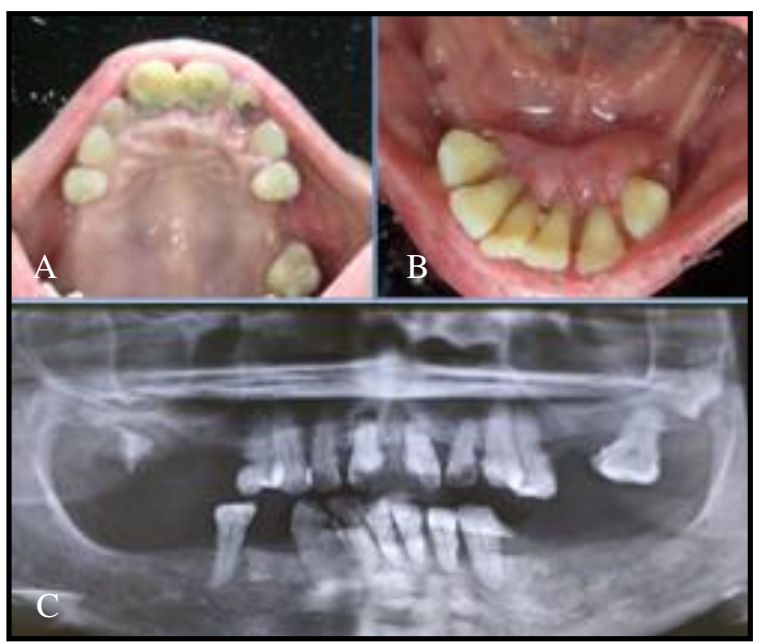

Figure 2. (A) Oklusal view (B) Upper Jow and (C) lower jaw, as well as panoramic photos of patient

\section{CASE MANAGEMENT(S)}

11, 21 and 22 that show a periapical lesions, advised to extract and it can improve the anterior tooth arrangement in the maxilla. In teeth 32 and 33 was non-immediate extraction performed because there are periapical lesions and deep caries were large enough with the presence of periapical abscesses. Scaling and root planing were performed on teeth 41,42 and 43 and root canal treatment (RCT) was performed and obtain to be a harmonious relationship between the upper and lower anterior teeth. After the RCT of 41,42,43 they are performed to cut off immediately and then restored with GIC on the surface. 


\section{Indonesian Journal of Dental Medicine}

Volume 1 Issue 1 2018; 49-53

The first stage is to conduct preliminary bite determination to get the appropriate maxillary and lower jaw relations. Followed by preliminary treatment including scaling and root planing in the periodontal field, patching of cavities (teeth 22), removal of non immediate teeth (tooth $31,32 \& 33$ ) and root canal treatment (RCT) in teeth 41.42 and 43.

The second stage is the process of making dentures, beginning with impression the maxillary and mandibular arches and produced with irreversible hydrocolloid to be a study model, making the individual tray, functional impressions, installation of working models in the articulator, making a bite rim and arranging the teeth, installing the wax, the presence of teeth in the work model, making and arranging teeth for the immediate dentures, and then acrylic packing.

The third stage, the immediate implementation of extraction and decaputation, began with the decaputation procedures of teeth 41,42 and 43 , namely the cutting of the ginggival crown of the tooth and then patching it right above the orifice from the root canal of decaputated teeth that had previously been carried out root canal treatment (endodontic treatment) (Figure 3a).

Immediate tooth extraction is carried out according to the tooth extraction procedure, namely before the extraction is measured the blood pressure is then carried out by local anesthetic by infiltration to extract teeth 11,21 and 22 (Figure 4a). After reacts of aneshtesia in the patient the extraction procedure was do in 11,21,22 with minimaly infassive (Figure $4 b)$ with an alveolar curretage (Figure 4c).

Acrylic dentures that were finished in the laboratory were immediately tested soon after the third stage of the procedure was completed (immediate tooth extraction and cutting of the crown of the teeth / immediate overdenture), refined areas of acrylic plates, especially in overdenture teeth and post extraction teeth, correcting the position of the retention clamp the maxilla. The patient is instructed to use the denture during the first 24 hours for the adaptation of the patient's oral cavity tissue, first control after 24 hours, 3 days and 1 week post insertion of the denture. Coping of the magnetic keeper (Figure 3b) installed after 1 week of complete denture insertion in the mandibular arch to increase retention and the insertion of maxillary immediate partial denture and mandibular complete overdenture with magnetic retention can we see in Figure 5. Than make a schedule for control in 1 day, 3 days and 1 week after magnetic insertion.

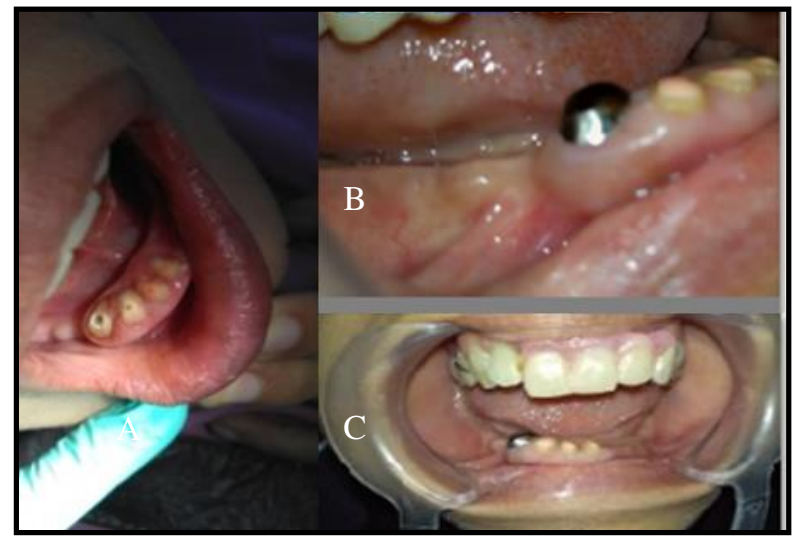

Figure 3. (A) The decaputation of the mandibular anterior teeth, (B-C) placing the koping keeper magnet on 43 


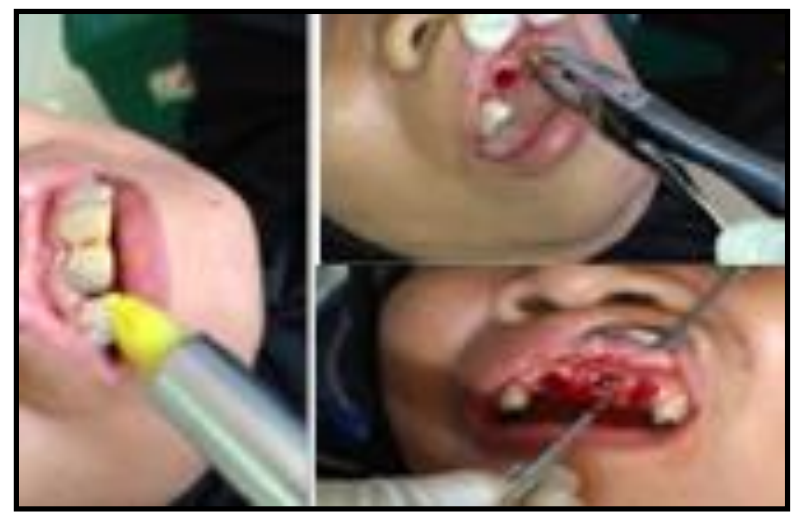

Figure 4. Stages of maxillary anterior tooth extraction: (A) Anasthetics stage, (B) extraction 11,21,22 and (C) alveolar curretage

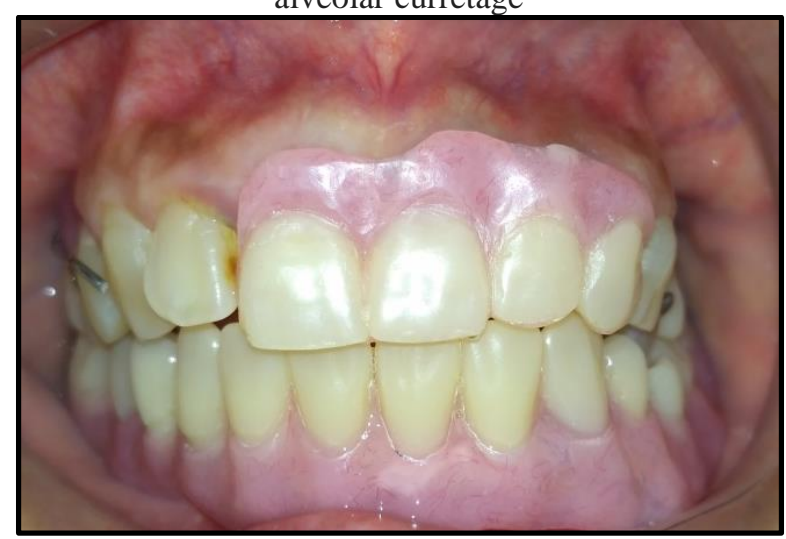

Figure 5. the insertion of maxillary immediate partial denture and mandibular complete overdenture with magnetic retention

\section{DISCUSSION}

In this case, the patient's teeth in the anterior maxilla and lower jaw were the majority who experienced unsteadiness which was a sign of a problem in their periodontal tissues. According to Siagian ${ }^{5}$, in the case of long-term loss of teeth, the remaining teeth often experience periodontal problems, such as mobility, changes in tooth position (protrusion, extrusion, rotation), and multiple diastema. Teeth 33,41,42 experienced shakiness $2^{\circ}$ and teeth 11,21 and 22 experienced unsteadiness $3^{0}$ in muller clasification of teet mobility ${ }^{6}$ accompanied by swelling and decreased alveolar bone height, although with these conditions the teeth were in the esthetic zone, therefore immediate extraction treatment was chosen in the anterior maxilla and an immediate bare root overdenture in the anterior mandible. Immediate denture is a denture made first and immediately inserted into the mouth of the patient immediately after extraction or decaputation of the tooth. ${ }^{4}$ The main objective of the immediate denture treatment is that patients avoid psychological, social and discomfort because they look toothless. ${ }^{3}$

In this case the patient is 55 years old. With a fairly old age, physical ability will decrease. The bare root overdenture was chosen with GIC restoration for time and visit efficiency of the patient. Overdenture can increase support and stability of the prosthesis, prolong the life of the support teeth and inhibit residual ridge resorption. ${ }^{7}$ Teeth $31,41,42$, and 43 were decaputated with dome shaped shapes. The dome shaped preparation type aims to avoid large lateral forces during the use of dentures, so that the abutment teeth do not increase shake. ${ }^{8}$ As a retention enhancer in 43 teeth, preparations are made to make a magnetic keeper coping that is inserted 1 day after inserting denture. ${ }^{9}$

After the insertion of the denture, the patient was instructed to always maintain the cleaning of the denture and the supporting teeth and tissues around the abutment teeth, because maintenance of periodontal tissue health is a determining factor in the success of overdenture treatment which also depends on 


\section{Indonesian Journal of Dental Medicine}

Volume 1 Issue 1 2018; 49-53

the effectiveness of plaque control carried out by the patient. ${ }^{9}$ Patients were also instructed for routine control every 6 months for topical application of fluoride in teeth with GIC bare root as fluoridation to prevent secondary caries. ${ }^{10}$ This case report showed that immediate denture is one of the treatment choice to improve the retention and facial aesthetic.

\section{REFERENCES}

1. Marinus. Treatment results with immediate overdenture : An evaluation of 4,5 years. J Prosthet Dent. 1996(76); p.153-7.

2. Leem HW, Cho IH, Lee JH, Choi YS. A Study on the changes in attractive force of magnetic attachments for overdentures. J Adv Prost. 2016,8; p.9-15.

3. Zarb G, Hobkirk JA, Eckert SE, Jacob RF. Prostodontics treatment for edentulous patient $13^{\text {th }}$ Ed. CV Mosby Co, St Louis. $2012: 22 ; \mathrm{p}$ $102-11$.

4. Bates,J.F and Stafford GD. Immediate Complete Denture. The British Dent Ass. London. 1971, 11 ; p.18-19.

5. Siagian KV. Kehilangan sebagian gigi pada rongga mulut. J ecl 2016.(4):1;p1-6.

6. Muller HP. Periodontology: the essential. Druckhaus Gutz.Germany. 2005;p177-9.

7. Brewer AA, Morrow RM. Overdenture. $2^{\text {nd }}$ Ed. St Louis:The CV Mosby Co. 1980;p3-11.

8. Jumber JF. An atlas of overdenture and attachment. Quintessence Pub Co Inc: Chicago. 1981; p 17, 20-3, 113-52.

9. Ai M, Shiau YY. New magnetic application in clinical dentistry. Quintessence pub Co ltd, Tokyo. 2004; p 28-69.

10. Hatim NA, Mohammed ST. Solving complete denture problem by the use of overdenture: clinical case report. Al-rafidain dent $\mathbf{J}$ 11(2):238-43. 